\title{
Preparation of an affinity cryogel column for lysozyme purification
}

\section{Lizzy Ayra Alcântara Veríssimo, Fernanda Spagnol Paganoto, Paula Chequer Gouveia Mol, Rafael da Costa Ilhéu Fontan, Valéria Paula Rodrigues Minim \& Luis Antonio Minim}

To cite this article: Lizzy Ayra Alcântara Veríssimo, Fernanda Spagnol Paganoto, Paula Chequer Gouveia Mol, Rafael da Costa Ilhéu Fontan, Valéria Paula Rodrigues Minim \& Luis Antonio Minim (2017) Preparation of an affinity cryogel column for lysozyme purification, Separation Science and Technology, 52:12, 1973-1982, DOI: 10.1080/01496395.2017.1318921

To link to this article: https://doi.org/10.1080/01496395.2017.1318921

Accepted author version posted online: 21

Apr 2017

Published online: 26 May 2017.

Submit your article to this journal \lceil

Џll Article views: 126

View Crossmark data $\complement$

Citing articles: 3 View citing articles $₫$ 


\title{
Preparation of an affinity cryogel column for lysozyme purification
}

\author{
Lizzy Ayra Alcântara Veríssimo , Fernanda Spagnol Paganotob, Paula Chequer Gouveia Molc, \\ Rafael da Costa Ilhéu Fontan ${ }^{b}$, Valéria Paula Rodrigues Minim ${ }^{d}$, and Luis Antonio Minim ${ }^{d}$
}

aDepartment of Food Science, Federal University of Lavras, Lavras, MG, Brazil; ${ }^{b}$ Processes Engineering Laboratory, State University of Southwest of Bahia, Itapetinga, BA, Brazil; 'Department of Food Engineering and Technology, UNESP- São Paulo State University, São José do Rio Preto, SP, Brazil; ${ }^{d}$ Department of Food Technology, Federal University of Viçosa, Viçosa, MG, Brazil

\section{ABSTRACT}

Affinity cryogels were synthesized using tris(hydroxymethyl)aminomethane (Tris) as ligand for specific interactions with the lysozyme (LYZ). The cryogel was produced by cryo-copolymerization at $-12^{\circ} \mathrm{C}$. A central composite rotational design $2^{2}$ was used to optimize the immobilization procedure of the Tris on the cryogel. A maximum adsorption for LYZ $(149.5 \mathrm{mg} / \mathrm{g})$ was achieved when $376 \mathrm{mg} / \mathrm{mL}$ of Tris and $3.06 \mathrm{~mol} / \mathrm{L}$ of sodium borohydride were used during the Tris immobilization. Chromatographic separation of LYZ from chicken egg white was done with a purity of $92.13 \%$. Results showed that the affinity cryogel was a potential separation medium for LYZ purification.

\section{ARTICLE HISTORY}

Received 18 October 2016

Accepted 10 April 2017

\section{KEYWORDS}

Adsorption; affinity chromatography; cryogel;

lysozyme; Tris

\section{Introduction}

Purification of biomolecules has increasingly aroused the interest of the researchers worldwide, given its potential for use in diverse fields such as the pharmaceuticals and foods. New techniques and materials have been developed, among them polymeric cryogels, which are considered the new generation of matrixes for chromatographic processes. $^{[1-6]}$

Among the materials available for use in purification processes is the supermacroporous monolithic cryogel. By presenting a highly porous structure, with large pores, this cryogel presents high permeability and low flow resistance. This matrix is an alternative to the direct purification of biocompounds from viscous means and non-clarified media, reducing the number of steps in the purification process and helping maintain the integrity of the compounds of interest. ${ }^{[2,4,5,7]}$

Despite the advantages presented by the cryogels, the large pores make the adsorption surface area smaller compared to a packaged fixed bed, which tends to lower its efficiency. Therefore, the study of cryogel surface modifications is a promising area and one that is developing rapidly. ${ }^{[1,2,5,7,8]}$ Modifications, whether chemical or physical, may be made aiming to increase the selectivity efficiency of the separation processes. ${ }^{[1,5,7,8]}$ Some modifications already studied involve immobilizing derivatives of acrylic acid, ${ }^{[9]}$ metals, ${ }^{[2,8,10]}$ sulfo group, ${ }^{[5,7]}$ aminoacids and proteins, ${ }^{[6]}$ among others in the polymeric matrix, increasing the retention capacity of the compounds. . $^{[1,2,5,7,8,11,12]}$

The lysozymes (EC 3.2.1.7) had bactericidal and bacteriostatic properties and are one of the few natural antimicrobial agents approved by regulatory agencies for use in foods. ${ }^{[13,14]}$ In addition to chicken egg white (CEW), the lysozyme (LYZ) is found in insects and mammals, including tissues and secretions such as tears, saliva, and others. ${ }^{[1,8,15]}$ Since their properties are well known and have been studied by the scientific community, lysozymes are widely used as protein standards in developing new materials and separation processes. $^{[15]}$

Several lysozyme purification techniques have been proposed, such as the use of ultrafiltration, affinity chromatography, and ion exchange systems as well as membranes and batches. All are geared toward higher degrees of purity and lower processing costs. ${ }^{[1,3,8,16-18]}$

Affinity chromatography is an effective technique for biomolecule purification and has the advantages of specifically selecting the target solute and single step purification. This differs from other techniques such as ionic exchange chromatography or hydrophobic interaction, precipitation, and ultrafiltration. ${ }^{[3,8,19]}$

Affinity chromatography for biomolecule purification on the industrial scale is not commonly used, however, mostly due to its high implementation cost. The classic ligands used in affinity columns, such as antibodies, metals, and pigments, have high costs. ${ }^{[3,8,19]}$ 
Quan et al. ${ }^{[20]}$ however reported the specific interaction between LYZ and the compound tris(hydroxymethyl) aminomethane (Tris). The authors showed that the force of this interaction is sufficient to retain the LYZ while also allowing the elution of this protein in moderate conditions and maintaining the native structure of the protein without loss of activity. ${ }^{[3,20]}$

In this study, an affinity cryogel was prepared containing tris(hydroxymethyl)aminomethane as the ligand group for lysozyme purification. Batch adsorption studies were done to optimize the adsorption capacity of the affinity cryogel for LYZ, and the morphological properties of the affinity cryogel were characterized. Chromatographic separation of lysozyme from chicken egg white was done using the affinity cryogel as column material in a liquid chromatography system.

\section{Materials and methods}

\section{Materials}

Lysozyme from chicken egg white (with purity greater than 90\%), tris(hydroxymethyl)aminomethane (Tris) $\left(\mathrm{C}_{4} \mathrm{H} 11 \mathrm{NO} 3\right)$, hydrochloric acid $(\mathrm{HCl})$, sodium hydroxide $(\mathrm{NaOH})$, methanol, sodium borohydride $(\mathrm{NaBH} 4)$, acetonitrile HPLC grade, trifluoroacetic acid, bovine serum albumin (BSA, 98\%), N,N, $\mathrm{N}^{\prime}, \mathrm{N}^{\prime}$ - tetra-methylethylenediamine (TEMED, 99\%), acrylamide (AAm, 99\%), $\mathrm{N}, \mathrm{N}^{\prime}$ - methylene-bis(acrylamide) (MBAAm, 99\%), allylglycidyl ether (AGE, 99\%), ammonium persulfate (APS, 98\%), sodium phosphate, and sodium chloride were purchased from Sigma-Aldrich (St. Louis, MO, USA). All other chemicals used were of analytical grade. Ultrapure water (Milli-Q System, Millipore, Bedford, MA, USA) was used in all the experiments.

\section{Cryogel preparation}

The cryogel was prepared according to Yao et al. ${ }^{[4]}$ Monomers of Aam (1.185 g) and BAam (0.3175 g) were mixed with deionized water. One $\mathrm{mL}$ of AGE was added to the monomer solution, and the final volume was completed to $25 \mathrm{~mL}$ using deionized water. The polymerization reaction was initiated by adding $100 \mu \mathrm{L}$ of APS solution $(27.5 \% \mathrm{w} / \mathrm{v})$ and TEMED $(23.8 \mu \mathrm{L})$ in an ice bath. The mixture was immediately poured into a C 10/20 glass column (GE Healthcare, Uppsala, Sweden). The column was sealed and immersed in an ethanol bath at $-12^{\circ} \mathrm{C}$ for $24 \mathrm{~h}$. Afterward, the column was thawed, washed with $1 \mathrm{~L}$ of deionized water, and then dried for $48 \mathrm{~h}$ at $60^{\circ} \mathrm{C}$.
Samples of dry cryogel were stored at room temperature until further experiments.

\section{Immobilization of the Tris ligand group to the cryogel column}

The affinity cryogel was prepared using Tris as a ligand group to assess the ability of the amino groups in the Tris molecule to bind covalently to epoxy groups present on the cryogel surface. ${ }^{[3,20]}$

Dry cryogel monoliths (approximately $0.6 \mathrm{~g}$ ) were added to centrifuge tubes containing $50 \mathrm{~mL}$ of pure methanol for $6 \mathrm{~h}$ at room temperature. For Tris coupling, the cryogels were incubated in $50 \mathrm{~mL}$ of potassium phosphate buffer $(0.0025 \mathrm{~mol} / \mathrm{L}, \mathrm{pH}$ 9.0) containing different concentrations $(\mathrm{mg} / \mathrm{mL})$ of Tris, as defined for each experimental condition (Table 1). Samples were kept at $60^{\circ} \mathrm{C}$ for $48 \mathrm{~h}$. Fifty $\mathrm{mL}$ of freshly prepared sodium borohydride solution (at different molar concentrations, as defined in Table 1) in sodium carbonate buffer $(0.2 \mathrm{~mol} / \mathrm{L}, \mathrm{pH} 9.2)$ were applied to the cryogels for $1 \mathrm{~h}$ in an ice bath to stabilize the covalent bonds formed between the Tris amino groups and the epoxy groups on the cryogel surface. ${ }^{[19]}$ The cryogels were washed with distilled water, squeezed to remove excess water, and kept in $0.5 \mathrm{~L}$ of ultrapure water for about $24 \mathrm{~h}$. The affinity cryogels were squeezed to remove excess water, dried for $48 \mathrm{~h}$ at $60^{\circ}$ $\mathrm{C}$, and stored at room temperature until the batch adsorption experiments. All procedures immobilizing the Tris ligand to the cryogel were done in batches.

\section{Batch adsorption studies}

Batch adsorption experiments were conducted in stirred tanks at $25^{\circ} \mathrm{C}$ for $24 \mathrm{~h}$. Dried affinity cryogel pieces of approximately $0.02 \mathrm{~g}$ were incubated in $0.5 \mathrm{~mL}$ of sodium phosphate buffer $(0.02 \mathrm{~mol} / \mathrm{L}, \mathrm{pH} 7.2)$ for $30 \mathrm{~min}$ to pre-equilibrate the adsorbents. Two point

Table 1. Experimental conditions of the design CCRD $2^{2}$ with four central points and obtained results.

\begin{tabular}{|c|c|c|c|}
\hline Assay & $X_{1}$ & $X_{2}$ & $\begin{array}{c}\text { Adsorption capacity } \\
\text { (mg/g dried affinity cryogel })\end{array}$ \\
\hline 1 & $-1(300)^{a}$ & $-1(2.22)$ & 95.7 \\
\hline 2 & $-1(300)$ & $+1(3.63)$ & 113.2 \\
\hline 3 & $+1(440)$ & $-1(2.22)$ & 113.3 \\
\hline 4 & $+1(440)$ & $+1(3.63)$ & 104.1 \\
\hline 5 & $-1.68(270)$ & $0(2.93)$ & 83.2 \\
\hline 6 & +1.68 (469) & $0(2.93)$ & 109.6 \\
\hline 7 & $0(370)$ & $-1.68(1.93)$ & 100.8 \\
\hline 8 & $0(370)$ & $+1.68(3.92)$ & 131.9 \\
\hline 9 & $0(370)$ & $0(2.93)$ & 153.8 \\
\hline 10 & $0(370)$ & $0(2.93)$ & 145.6 \\
\hline 11 & $0(370)$ & $0(2.93)$ & 149.9 \\
\hline 12 & $0(370)$ & $0(2.93)$ & 135.3 \\
\hline
\end{tabular}

${ }^{a}$ Numbers in parenthesis represent uncoded experimental values. 
five $\mathrm{mL}$ of pure $\mathrm{LYZ}$ solution $(1 \mathrm{mg} / \mathrm{mL})$ in sodium phosphate buffer were added to the tubes. The tubes were stirred for $24 \mathrm{~h}$, and samples of the supernatant were collected. All experiments were done in triplicate.

To determine the adsorption capacity of the affinity cryogel for LYZ, the initial and final concentrations of LYZ were determined with the Bradford method. ${ }^{[21]}$ The analytical curve was constructed using standard lysozyme solutions at concentrations ranging from $0.1 \mathrm{mg} / \mathrm{mL}$ to $1.0 \mathrm{mg} / \mathrm{mL}$.

The amount of LYZ adsorbed was calculated by Eq. (1).

$$
q=\frac{\left(C_{0}-C\right) S}{M}
$$

where $\mathrm{q}$ is the final concentration of lysozyme in the dried cryogel $(\mathrm{mg} / \mathrm{g}) ; C_{0}$ and $C$ are the initial and the final lysozyme concentrations in the pure LYZ solution $(\mathrm{mg} / \mathrm{mL}) ; M$ is dried cryogel weight $(\mathrm{g})$; and $S$ is the volume of the solution $(\mathrm{mL})$.

\section{Experimental design and statistical analyses}

The factors that were considered to affect the immobilization of the Tris ligand group on the cryogel surface, which consequently affected the adsorption capacity of the affinity column for LYZ, were chosen based on the results of Quan et al. ${ }^{[3,20]}$ Based on previous experiments, we chose to use the reducing agent $\mathrm{NaBH}_{4}$ in place of the blocking agent Tris-HCl.

The adsorption capacity of the affinity cryogel for LYZ was optimized using response surface methodology (RSM). To evaluate the effect of the Tris concentration $\left(X_{1}\right)$ and sodium borohydride molar concentration $\left(X_{2}\right)$ on the response variable adsorption capacity of the affinity cryogel for LYZ, a Central Composite Rotatable Design (CCRD) $2^{2}$ was applied with four replications at central points to estimate experimental error. For this design, the original (uncoded) and coded variables, as well as each level, are shown in Table 1.

The experimental results obtained from the CCRD (Table 1) were analyzed by regression procedure (PROC GLM, SAS Institute Inc., v. 9.0, Cary, NC, USA) using the following second order polynomial equation (Eq. (2)):

$$
Y=\beta_{0}+\sum \beta_{i} X_{i}+\sum \beta_{i i} X_{i}^{2}+\sum \beta_{i j} X_{i} X_{j}+e
$$

where $Y$ is the response variable (adsorption capacity, $\mathrm{mg} / \mathrm{g}) ; \beta_{0}$ is the model intercept; $X_{i}$ and $X_{j}$ are the levels of the independent variables; $e$ is the error; and $\beta_{i}, \beta_{i i}$, and $\beta_{i j}$ are the linear, quadratic, and interaction coefficients.
The adequacy of the model was determined by evaluating the lack of fit, coefficient of determination $\left(R^{2}\right)$, and Fisher's test (F-value) obtained from the analysis of variance (ANOVA). Student's t-test was performed for each estimate parameter. Parameters with less than 95\% significance $(p>0.05)$ were pooled into the error term. Results associated with the RSM were used to visualize the effect of the factors on the adsorptive capacity and to maximize this response.

All statistical analyses were performed with the statistical package Statistical Analysis System version 9.0 (SAS Institute Inc., Cary, NC, USA), licensed by the Federal University of Viçosa. The module used to construct the matrix with the experimental conditions was SAS 9.0/ $\mathrm{ADX}^{\circledast}$ (Interface for Design of Experiments). The contour plot was generated by the SigmaPlot software version 11.0 for Windows (Systat Software, Inc., Point Richmond, California, USA).

\section{Effect of flow rate on $L Y Z$ adsorption from aqueous solution}

After obtaining the best conditions for immobilizing Tris ligand, the effect of the flow rate $(0.5,1.0,2.0$, and $3.0 \mathrm{~mL} / \mathrm{min}$ ) of the pure LYZ aqueous solution on the LYZ absorbed by the affinity column was evaluated. The breakthrough behavior of LYZ in the affinity cryogel was performed at $25^{\circ} \mathrm{C}$, using a C $10 / 20$ column (GE Healthcare Uppsala, Sweden) on an ÄKTA Pure $25 \mathrm{M}$ chromatographic system (GE Healthcare Bio-Sciences $\mathrm{AB}$, Uppsala, Sweden). Columns were equilibrated by washing with five column volumes of sodium phosphate buffer (0.02 mol/L, pH 7.2). A lysozyme solution (1 mg/ $\mathrm{ml}$ in sodium phosphate buffer $0.02 \mathrm{~mol} / \mathrm{L}$ at $\mathrm{pH} 7.2$ ) was passed through the column, and the chromatography process was monitored by a UV spectrometer at $280 \mathrm{~nm}$. The column was washed with five column volumes of equilibrium buffer. The elution procedure was performed by washing with ten column volumes of sodium phosphate buffer $(0.02 \mathrm{~mol} / \mathrm{L}, \mathrm{pH} 7.2)$ containing $\mathrm{NaCl}(1.0 \mathrm{~mol} / \mathrm{L})$. The solution eluted from the column was collected in a fraction collector, and the LYZ content was determined by the Bradford method. ${ }^{[21]}$ The amount of LYZ adsorption per unit mass of the cryogel was calculated using the mass balance (Eq. (1)). All adsorption experiments were done in triplicate.

\section{Purification of lysozyme from chicken egg white}

\section{Preparation of chicken egg white solution}

Chicken egg white was manually separated from fresh eggs. The egg white was filtered through a sieve $(15 \mathrm{~cm}$ diameter $\times 1.0 \mathrm{~mm}$ mesh opening) in order to remove 
the chalazae. One hundred ninety $\mathrm{mL}$ of filtered CEW was diluted with $380 \mathrm{~mL}$ of mili-Q water, and the $\mathrm{pH}$ was adjusted to 6.0 using $\mathrm{HCl}(2 \mathrm{~mol} / \mathrm{L})$. The diluted CEW was homogenized and centrifuged at $12000 \times g$ for $10 \mathrm{~min}$ at $4^{\circ} \mathrm{C}$. The supernatants were collected, and the following solutions were prepared: $5 \mathrm{~mL}$ of sodium phosphate buffer $(1.0 \mathrm{~mol} / \mathrm{L}, \mathrm{pH} 7.2)$ was added to $250 \mathrm{~mL}$ of diluted egg white (dilution 1:2); $156 \mathrm{~mL}$ of sodium phosphate buffer $(0.032 \mathrm{~mol} / \mathrm{L}, \mathrm{pH} 7.2)$ was added to $94 \mathrm{~mL}$ of diluted egg white (dilution 1:7); and $210 \mathrm{~mL}$ of sodium phosphate buffer $(0.024 \mathrm{~mol} / \mathrm{L}$, $\mathrm{pH}$ 7.2) was added to $40 \mathrm{~mL}$ of diluted egg white (dilution 1:18). In all dilutions, the final concentration of sodium phosphate buffer was $0.02 \mathrm{~mol} / \mathrm{L}$. $\mathrm{pH}$ values were checked and adjusted to 7.2 as necessary using $\mathrm{NaOH}$ solution $(2.0 \mathrm{~mol} / \mathrm{L})$. The solutions were centrifuged again at $12000 \times \mathrm{g}$ for $15 \mathrm{~min} 4^{\circ} \mathrm{C}$, and the supernatants were carefully separated from the precipitate using a pipette. The solutions were refrigerated until further use.

\section{Chromatographic purification assays}

Chromatographic purification of lysozyme from the CEW solution was done at a constant flow of $0.5 \mathrm{~mL} /$ $\mathrm{min}$ at room temperature. Purification assays were done with the ÄKTA Pure $25 \mathrm{M}$ chromatographic system, as described in section "Effect of flow rate on LYZ adsorption from aqueous solution." The diluted egg white solutions were pumped through the affinity column until the breakthrough curves formed. Column effluents were collected for further analysis. The elution procedure was performed, and the solution eluted from the column was collected. LYZ content was determined by high performance liquid chromatography (HPLC). ${ }^{[22]}$ Total protein content was determined by the Bradford method. $^{[21]}$ All chromatographic purification experiments were done in triplicate.

\section{Quantification of lysozyme from chicken egg white} Lysozyme quantification from the CEW solutions and eluted columns taken from the chromatographic purification experiments were done by HPLC using a liquid chromatograph (Shimadzu, Japan) at a wavelength of $220 \mathrm{~nm}$. A reverse phase column (C18 Shim-pack VP-ODS, $250 \times 4.6 \mathrm{~mm}$, Shimadzu) was used for chromatographic separation, with the mobile phases composed of pure acetonitrile and $0.1 \%(\mathrm{v} / \mathrm{v})$ of trifluoroacetic acid solution, at a flow rate of $0.5 \mathrm{~mL} /$ $\min$ at $30^{\circ} \mathrm{C}$. The samples were filtered through an acetate cellulose membrane $(0.22 \mu \mathrm{m})$. A volume of $50 \mu \mathrm{L}$ was injected directly into the chromatograph, and the proteins were eluted from the column using the gradient method. ${ }^{[22]}$ Total protein content was determined as being the total area of the peaks obtained in each chromatogram.

To evaluate the efficiency of LYZ captured from the CEW by affinity cryogel, we determined the recovery (\%), purity degree (\%), and purification factor parameters.

The recovery (\%) was calculated as the ratio between the LYZ mass recovered $\left(m_{L Y Z, r e c}\right)$ in the sample eluted from the column and the LYZ mass in CEW dilution $\left(m_{L Y Z, p e r c}\right)$ that percolated through the affinity cryogel (Eq. (3)).

$$
\text { Recovery }=\frac{m_{L Y Z, r e c}}{m_{L Y Z, \text { perc }}} \times 100
$$

The degree of purity (Purity, \%) was determined from the ratio between the LYZ mass recovered $\left(m_{L Y Z, r e c}\right)$ and the total protein content recovered $\left(m_{P R O T, r e c}\right)$ in the sample eluted from the column (Eq. (4)).

$$
\text { Purity }=\frac{m_{L Y Z, \text { rec }}}{m_{P R O T, \text { rec }}} \times 100
$$

The purification factor $\left(P_{F}\right)$ was determined from the ratio of the LYZ purity in the sample eluted from the column and the LYZ purity in the CEW solution (Eq. (5)).

$$
P_{F}=\frac{\left(\frac{m_{L Y Z, r e c}}{m_{P R O T, \text { rec }}}\right)}{\left(\frac{m_{L Y Z, C E W}}{m_{P R O T, C E W}}\right)}
$$

where $m_{L Y Z, C E W}$ is the LYZ mass in the CEW solution, and $m_{P R O T, C E W}$ is the total protein content in the CEW solution.

The LYZ purity in the fractions collected from the chromatographic purification experiments was also assayed by Sodium dodecyl sulfate-polyacrylamide gel electrophoresis (SDS-PAGE), using a vertical gel electrophoresis system (E-C Apparatus Corporation, St. Petersburg, FL, USA). The acrylamide gel was prepared as a $15 \%$ separating gel in $1.5 \mathrm{M}$ Tris- $\mathrm{HCl}(\mathrm{pH} 8.8)$ and a $5 \%$ stacking gel in $1.0 \mathrm{M}$ Tris- $\mathrm{HCl}$ ( $\mathrm{pH}$ 6.8). All samples were treated with tris- $\mathrm{HCl}$ buffer containing SDS, bromophenol blue, glycerol, and $\beta$ mercaptoethanol and heated at $90^{\circ} \mathrm{C}$ for $10 \mathrm{~min}^{[23]}$ Aliquots of $30 \mu \mathrm{L}$ were subjected to a voltage of $100 \mathrm{~V}$ for $4 \mathrm{~h}$ and colored with Comassie blue.

\section{Characterization of the affinity cryogel}

Affinity cryogel porosity (Ø) was estimated by measuring the free water content and volume of the cryogel, according to Yao et al. ${ }^{[24]} \mathrm{A}$ sample of about $2.5 \mathrm{~cm}$ in length was cut from the middle of the monolithic cryogel and saturated with deionized water. The sample was then immersed in a graduated cylinder containing deionized water with a previously known volume $\left(V_{1}\right)$, with new volume $\left(V_{2}\right)$ measured after immersion. The 
sample volume $\left(V_{0}\right)$ was calculated by subtracting both volumes, that is, $V_{0}=V_{2}-V_{1}$. The mass of the sample saturated with water $\left(m_{w}\right)$ was determined. The cryogel was gently compressed to remove the free water within the large pores, and the mass of the sample without free water $\left(m_{c}\right)$ was weighed. Porosity was calculated according to $\mathrm{Eq}(6)$ :

$$
\emptyset=\frac{\left(m_{w}-m_{c}\right)}{\rho_{w} V_{0}}
$$

where $\rho_{w}$ is the deionized water density. The cryogel was dried at $60^{\circ} \mathrm{C}$ in a BOD incubator until constant mass. The dry mass $\left(m_{d}\right)$ was measured and used to calculate the swelling capacity $\left(S_{w / w}\right)$ according to Eq. $(7)^{[25]}$.

$$
S_{w / w}=\frac{\left(m_{w}-m_{d}\right)}{m_{d}}
$$

The flow resistance provided by the affinity cryogel column was determined by Darcy's law, according to Eq. (8). The hydrostatic pressure drop through the column was measured at a different flow rate than the mobile phase $\left(0.83 \times 10^{-8}-16.7 \times 10^{-8} \mathrm{~m}^{3} / \mathrm{s}\right)$, using the ÄKTA Pure $25 \mathrm{M}$ chromatographic system. Hydraulic permeability, $K_{w}$, was obtained by the angular coefficient with Eq. (8):

$$
\frac{\Delta P_{w}}{L}=-\frac{\mu_{w}}{K_{w}} \cdot U
$$

where $K_{w}\left(\mathrm{~m}^{3} / \mathrm{s}\right)$ is the water flow rate through the column, $\mu_{w}$ is the water viscosity (Pa.s), $L$ is the column length $(\mathrm{m}), U$ is the cross-section area $\left(\mathrm{m}^{2}\right)$, and $\Delta P_{w}$ is the pressure drop through the column $(\mathrm{Pa})$.

Residence time distribution (RTD) at various liquid superficial velocities $(0.0001$ to $0.002 \mathrm{~m} / \mathrm{s})$ was measured in a chromatographic system (ÄKTA Pure) using the pulse method. The mobile phase was composed of deionized water, and a pulse of $500 \mu \mathrm{L}$ of acetone solution $(1 \% \mathrm{v} / \mathrm{v})$ was injected in the column, with the absorbance monitored at $280 \mathrm{~nm}$. All analyses were done in triplicate. The axial dispersion coefficients of each flow rate were determined from the RTD curves. Residence time and variance were obtained from the curves, and axial dispersion coefficients were determined by numerical resolution (Eq. (9)).

$$
\frac{\sigma_{t}^{2}}{t_{R}^{2}}=2\left(\frac{D_{a x}}{u L}\right)-2\left(\frac{D_{a x}}{u L}\right)^{2}\left[1-\exp \left(\frac{-u L}{D_{a x}}\right)\right]
$$

where $\sigma^{2}$ and $t_{R}$ are the variance $\left(s^{2}\right)$ and the residence time (s) of the RTD curve, $D_{a x}$ is the axial dispersion coefficient $\left(\mathrm{m}^{2} / \mathrm{s}\right)$ at a given flow rate, $L$ is the column length $(\mathrm{m})$, and $u$ is the interstitial velocity $(\mathrm{m} / \mathrm{s})$ of the mobile phase through the column $\left.\left(u=U_{L} / \emptyset\right)\right)$. $U_{L}$ is the superficial velocity $(\mathrm{m} / \mathrm{s})$, and $\emptyset$ is the cryogel porosity.

The theoretical plate number of the column $(\mathrm{N})$ was calculated from the RTD results, and the values for the height equivalent for a theoretical plate (HETP) were obtained from the calculated column length. ${ }^{[4]}$

Affinity cryogel morphology was evaluated by scanning electron microscopy (SEM). The cryogel was dehydrated at $60^{\circ} \mathrm{C}$ for $48 \mathrm{~h}$, and a small sample cut from the middle part of the dried cryogel was coated with gold/palladium (40/60). The cryogel structure was examined using a scanning electron microscope (LEO 1430 VP, Zeiss, Jena, Germany).

\section{Results and discussion}

\section{Immobilization of Tris ligand group in the cryogel column}

A CCRD $2^{2}$ was applied to optimize the factors that affect the immobilization of Tris ligand group on the cryogel surface. Results are presented in Table 1. The maximum adsorption capacity values for LYZ found in this work were greater than those found by Zhang et al. ${ }^{[26]}(108.6 \mathrm{mg} / \mathrm{g})$ with the system composed of tris(hydroxymethyl)aminomethane-modified magnetic microspheres. Therefore, these preliminary results indicate the suitability of this system for LYZ purification.

Experimental results were subjected to ANOVA, and the results (in terms of uncoded variables) are presented in Table 2. It was shown that the factors Tris concentration $\left(X_{1}\right)$ and sodium borohydride molar concentration $\left(X_{2}\right)$, as well as their quadratic effects $\left(X_{1} * X_{1}\right.$ and $\left.X_{2} * X_{2}\right)$, significantly affected $(\mathrm{p}<0.05)$ adsorption capacity. Factors that were not statistically significant $(\mathrm{p}>0.05)$ were aggregated in the error term. A mathematical model (Eq. (10)), in terms of uncoded variables, was obtained by regression analyses, using only significant $(\mathrm{p}<0.05)$ factors.

The coefficient of determination $\left(R^{2}\right)$ was 0.92 , and the lack of fit was non-significant $(\mathrm{p}>0.05)$, indicating the suitability of the models.

$$
\begin{aligned}
q= & -914.25+4.018 * X_{1}+198.86 * X_{2} \\
& -0.0053 * X_{1} * X_{1}-32.41 * X_{2} * X_{2}
\end{aligned}
$$

where $q$ is the adsorption capacity $(\mathrm{mg} / \mathrm{g}$ ) of the affinity cryogel for LYZ, $X_{1}$ is the concentration of Tris $(\mathrm{mg} /$ $\mathrm{mL}$ ), and $X_{2}$ is the molar concentration of sodium borohydride ( $\mathrm{mol} / \mathrm{L})$.

Response surface methodology allowed the evaluation of the experimental conditions where the adsorption capacity of the affinity cryogel for LYZ was maximized. Figure 1 shows the contour plot graph of 
Table 2. ANOVA performed on the results of adsorption capacity of the affinity cryogel.

\begin{tabular}{lrcccc}
\hline Source & $\mathrm{DF}^{\mathrm{a}}$ & $\mathrm{SS}^{\mathrm{b}}$ & $\mathrm{MS}^{\mathrm{c}}$ & F-value & p-value \\
\hline$X_{1}$ & 1 & 262.6 & 262.6 & 3.75 & 0.0940 \\
$X_{2}$ & 1 & 343.2 & 343.2 & 4.90 & 0.0624 \\
$X_{1 *} X_{1}$ & 1 & 4348 & 4347 & 62.10 & 0.0001 \\
$X_{2 *} X_{2}$ & 1 & 1660 & 1660 & 23.72 & 0.0018 \\
Model & 4 & 5745 & 1436 & 20.52 & 0.0006 \\
Error & 7 & 490 & 70.0 & & \\
Lack of fit & 4 & 441 & 110 & 6.82 & 0.0734 \\
Pure error & 3 & 48.6 & 16.2 & & \\
Total & 11 & 6234 & & & \\
\hline
\end{tabular}

${ }^{\mathrm{a} D F}$ : degrees of freedom; ${ }^{\mathrm{b}} \mathrm{SS}$ : sum of squares; ${ }^{\mathrm{C} M S}$ : mean of squares.

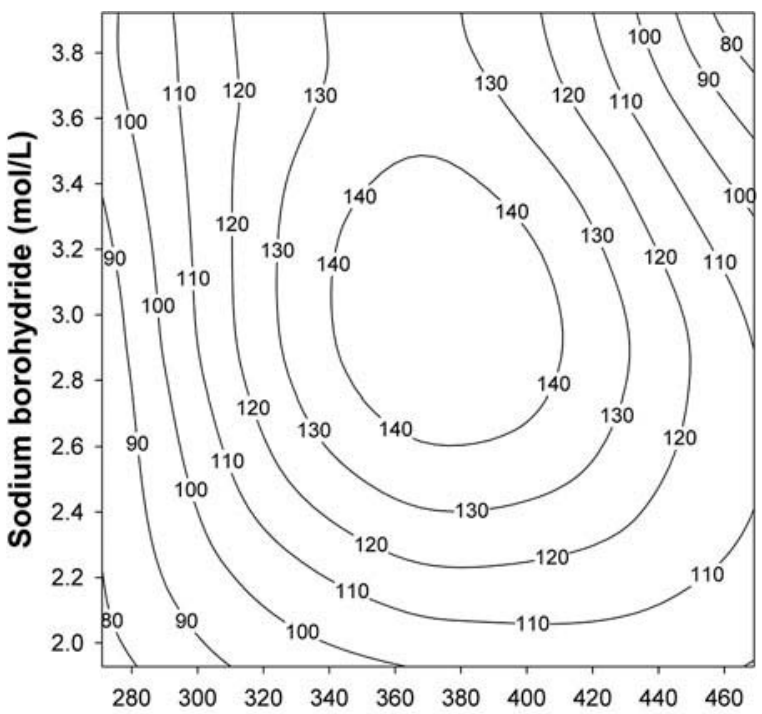

Tris(hydroxymethyl)aminomethane $(\mathrm{mg} / \mathrm{mL})$

Figure 1. Contour plot of the combined effects of concentration of Tris(hydroxymethyl)aminomethane $(\mathrm{mg} / \mathrm{mL})$ and the molar concentration of sodium borohydride $(\mathrm{mol} / \mathrm{L})$ on the adsorption capacity of the cryogel.

the combined effect of concentration of Tris $(\mathrm{mg} / \mathrm{mL})$ and the molar concentration of sodium borohydride solution $(\mathrm{mol} / \mathrm{L})$ on the adsorption capacity $(\mathrm{mg} / \mathrm{g})$ of the affinity cryogel.

As shown in Fig. 1, the Tris concentration and sodium borohydride molar concentration increased to $376 \mathrm{mg} / \mathrm{mL}$ and $3.06 \mathrm{~mol} / \mathrm{L}$, resulting in a higher adsorption capacity for LYZ.

According to Zhang et al., ${ }^{[26]}$ the chemical activity of the free epoxy groups present on the cryogel surface allows the easy attachment of the specific ligand groups, such as Tris. This attachment is facilitated by the fact that the ring of the epoxy group is pulled taut, resulting in the instability of these structures, which may be broken with relative ease. Moreover, the initial treatment of the cryogels with methanol, a weak nucleophillic, provided an opening in the cryogel epoxy group rings, ${ }^{[27]}$ further facilitating the bond between the amino groups $\left(\mathrm{NH}_{2}\right)$ in the Tris molecule and the epoxy groups present on the cryogel surface.

Thus, the increase in the Tris concentration (up to $376 \mathrm{mg} / \mathrm{mL}$ ) in the potassium phosphate buffer solution $(0.0025 \mathrm{~mol} / \mathrm{L}, \mathrm{pH} 9.0)$ during the ligand immobilization step provided an increased in the adsorptive capacity of the cryogel, since more Tris groups were immobilized on the cryogel surface, increasing the number of reactive sites for lysozyme adsorption, by means of specific interactions between the three hydroxyl groups of the Tris molecule and the aminoacids Aspartic acid 52, Glutamic acid 35, and Alanine 107 of LYZ. ${ }^{[20]}$

The effect of the molar concentration of sodium borohydride on the adsorptive capacity of the cryogel for LYZ may be related to the fact that the residual epoxy groups, which did not react with Tris, may have been reduced to alcohol by means of borohydride action. As a result of this reaction, new hydroxyl groups may be available to interact with the lysozyme. Therefore, the increase in the molar concentration of borohydride to $3.06 \mathrm{~mol} / \mathrm{L}$, to immobilize the Tris groups to the cryogel surface, may have resulted in the formation of new hydroxyl groups from epoxy groups that did not bond to the Tris group and are free to undergo the hydrogenolysis reaction. ${ }^{[28]}$

Despite the specific interaction between the lysozyme and the multi-hydroxyl ligand Tris that occurs due to the hydrogen bonds among the amino acids Asp52, Glu35, and Ala107 of the lysozyme and triad of hydroxyls $(\mathrm{OH})$ present in the structure of Tris, Cao et al. ${ }^{[29]}$ studied the potential for use of small molecules, such as Tris, serinol, and ethanolamine, as ligands for protein separation using a quartz crystal microbalance biosensor. They observed that the LYZ interacts with the hydroxyl groups of the evaluated ligands. Among the three multi-hydroxyl amine ligands studied, however, Tris was considered the best ligand for weak affinity separation of LYZ, since it presented the highest resolution values in the separation of protein mixtures containing myoglobin, cytochrome $c(C y t c)$, and LYZ.

The optimum conditions obtained from the adjusted model indicate that the adsorption capacity for LYZ is maximized at experimental conditions of $376 \mathrm{mg} / \mathrm{mL}$ of Tris and $3.06 \mathrm{~mol} / \mathrm{L}$ of sodium borohydride. At these conditions, the predicted value for $q$ is $149.50 \mathrm{mg} / \mathrm{g}$ of dried affinity cryogel.

\section{Effect of flow rate on LYZ adsorption from aqueous solution}

Experimental results on the amount of adsorbed lysozyme $(\mathrm{mg} / \mathrm{g})$ at different flow rates are presented in Fig. 2. 


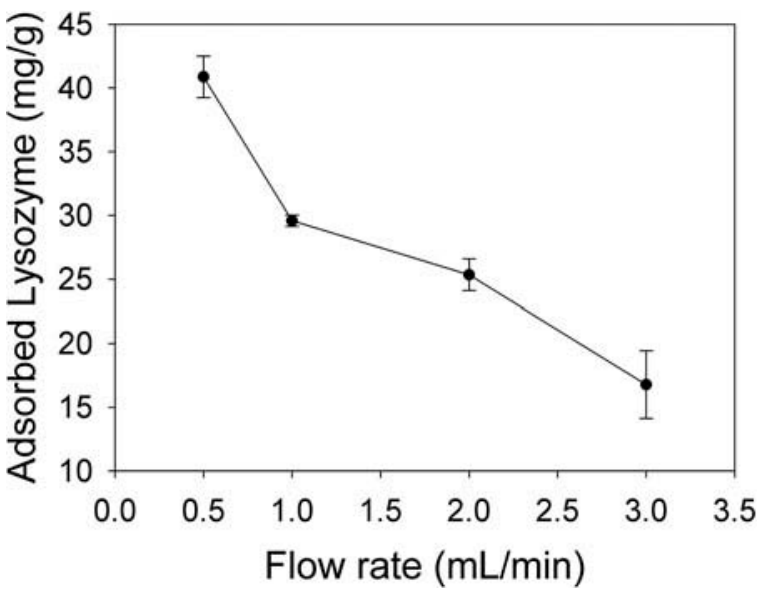

Figure 2. Effect of flow rate on the adsorbed LYZ in affinity cryogel. Lysozyme concentration: $1.0 \mathrm{mg} / \mathrm{mL}$; $\mathrm{pH}$ : 7.2, phosphate buffer $0.02 \mathrm{~mol} / \mathrm{L}$; at room temperature.

As shown in Fig. 2, the increase of the flow rate from 0.5 to $3.0 \mathrm{~mL} / \mathrm{min}$ resulted in a reduction of the quantity of LYZ adsorbed by the affinity cryogel from 40.88 to $16.78 \mathrm{mg} / \mathrm{g}$. This same behavior was observed by Bereli et al. ${ }^{[30]}$ and Türkmen and Denizli, ${ }^{[1]}$ who studied the adsorption of lysozyme in cryogels.

This behavior may be explained by the shorter contact time between the LYZ and the affinity cryogel at higher flower rates. At a lower flow rate $(0.5 \mathrm{~mL} /$ $\mathrm{min}$ ), the molecules of LYZ have a longer time to diffuse through the column pores and bond to the ligand groups, which result in a higher quantity of lysozyme adsorbed. ${ }^{[1,30]}$

\section{Purification of lysozyme from chicken egg white}

To demonstrate the feasibility of the affinity cryogel column on LYZ purification from a real sample, the CEW diluted solution was used as a lysozyme source. Table 3 shows the parameters obtained for LYZ purification process using CEW feed solutions at different dilution ratios. In all experiments, the standard deviation was less than $5 \%$.

According to Table 3, it was shown that the quantity of LYZ adsorbed, the purity degree, the purification factor, and the recovery degree increased as more diluted egg white solutions were used. By using the more concentrated egg white solution, the high concentration of proteins in the medium may have provided steric hindrance effects, blocking the access of the lysozyme to the adsorption sites, or possible effects of LYZ interaction with non-adsorbed proteins ${ }^{[31,32]}$ may have contributed to a lower value of LYZ adsorbed and recovered. In addition to this, in the most diluted CEW solutions, the proteins are spaced further apart, the effects of steric hindrance are reduced, and as a consequence higher values of LYZ adsorbed, recovery, degree of purity, and factor of purification are obtained.

The purity degree and the purification factor obtained for the most diluted egg white solution (1:18) reached values close to $92 \%$ purity, and one final sample was almost 10 times more pure than the initial feeding. The purity degree reached is close to that of other studies involving the purification of lysozyme from solutions of diluted egg white. $^{[1,6,33]}$

The CEW solutions and the eluted samples taken from the affinity column were analyzed by SDS-PAGE, as shown in Fig. 3. In the diluted CEW solution (lines 2, 4, and 6), the three major proteins (conalbumin, ovalbumin, and lysozyme) were detected, whereas the samples eluted from the affinity column (lines 3, 5, and 7) presented only one strong protein band at around $14.3 \mathrm{kDa}$ that corresponded to LYZ, indicating an elevated ligation capacity and selectivity of the affinity cryogel toward the lysozymes.

The chromatograms of the diluted CEW solution before the purification process and the eluted sample taken from the affinity cryogel column after the purification process are shown in Fig. 4.

As shown in Fig. 4(B), only LYZ was detected in the eluted sample, while LYZ and others proteins were present in the CEW feed solution (Fig. 4(A)). Moreover, it may be observed that the LYZ was concentrated in the eluted sample (Fig. 4(B)). Therefore, the proposed affinity cryogel column may provide a selective and effective means of separation for single step chromatographic purification of lysozyme from diluted chicken egg white.

\section{Affinity cryogel characterization}

Hydraulic permeability is related to the resistance offered by the porous bed, and the higher the value of

Table 3. Experimental results obtained from chromatographic purification of LYZ from the CEW by Tris affinity column.

\begin{tabular}{lcccccc}
\hline $\begin{array}{l}\text { CEW dilution } \\
\text { ratio }\end{array}$ & $\begin{array}{c}\mathrm{LYZ} \text { content }(\mathrm{mg} / \mathrm{mL}) \text { on } \\
\text { Feed solution }\end{array}$ & $\begin{array}{c}\mathrm{LYZ} \text { content }(\mathrm{mg} / \mathrm{mL}) \text { on } \\
\text { eluted solution }\end{array}$ & $\begin{array}{c}\text { Adsorbed } \mathrm{LYZ} \\
(\mathrm{mg} / \mathrm{g})\end{array}$ & $\begin{array}{c}\text { Recovery } \\
(\%)\end{array}$ & $\begin{array}{c}\text { Purity } \\
(\%)\end{array}$ & $\mathrm{P}_{\mathrm{F}}$ \\
\hline $1: 2$ & 1.34 & 0.63 & 6.83 & 8.91 & 79.0 & 5.9 \\
$1: 7$ & 0.47 & 1.37 & 15.07 & 18.8 & 87.1 & 7.9 \\
$1: 18$ & 0.08 & 1.35 & 18.98 & 97.6 & 92.1 & 9.9 \\
\hline
\end{tabular}




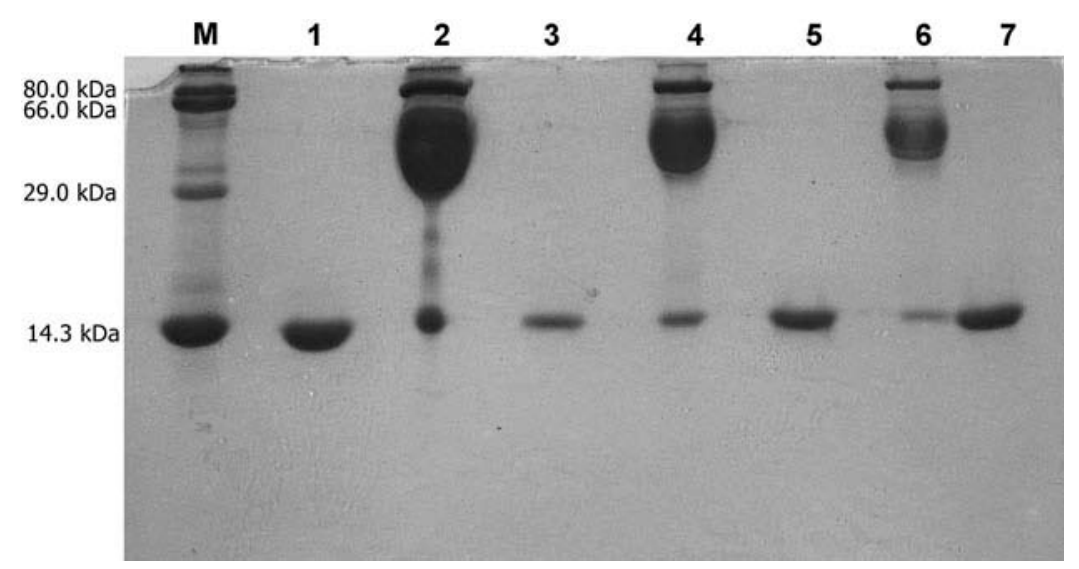

Figure 3. SDS-PAGE analysis of chromatographic isolation process of LYZ from CEW by affinity cryogel with one-step elution. M: molecular marker; Lane 1: pure LYZ (3 mg/mL); Lane 2: Feed solution of CEW at dilution 1:2; Lane 3: peak fraction from elution of feed solution of CEW at dilution 1:2; Lane 4: Feed solution of CEW at dilution 1:7; Lane 5: peak fraction from elution of feed solution of CEW at dilution 1:7; Lane 6: feed solution of CEW at dilution 1:18; Lane 7: peak fraction from elution of feed solution of CEW at dilution 1:18.
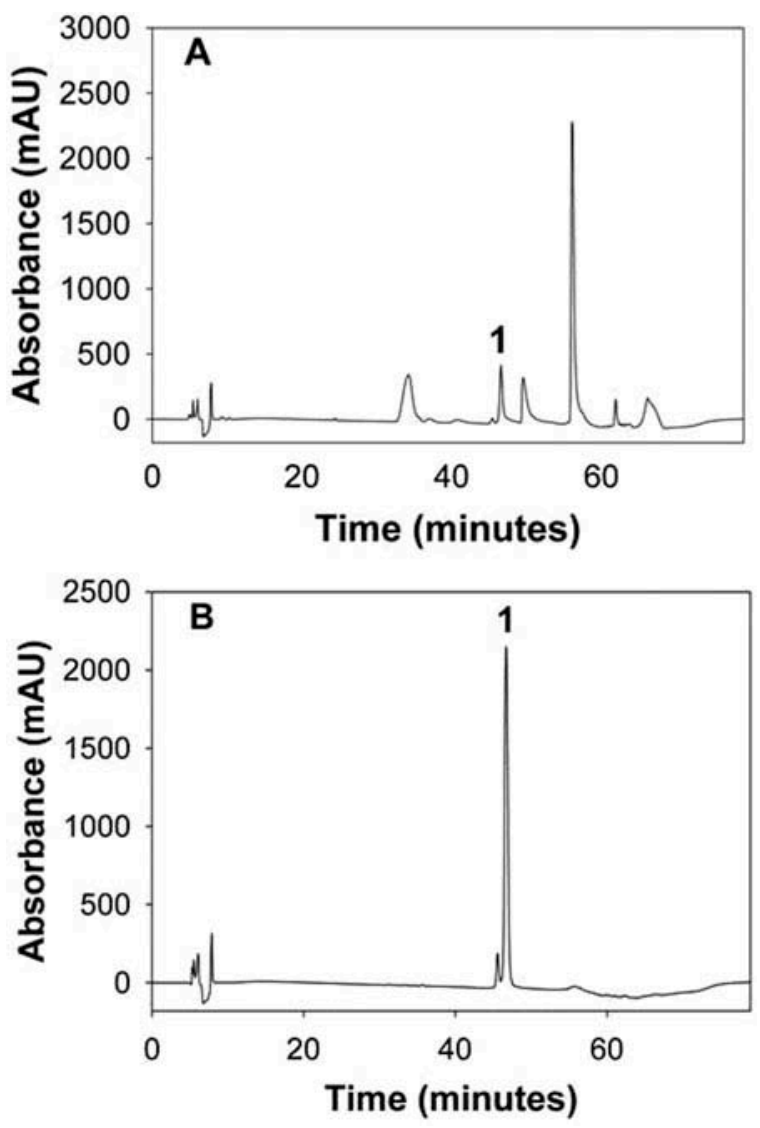

Figure 4. Chromatographic profile of lysozyme purified in affinity cryogel column. (A) Feed solution of CEW at dilution 1:18; Eluted sample of feed solution of CEW at dilution 1:18. Chromatographic peak 1 corresponds to LYZ (retention time $=47.744 \mathrm{~min}$ ). All LYZ quantification procedures were done in a $\mathrm{C} 18$ column reverse phase (Shim-pack VP-ODS, Shimadzu).

this parameter, the lower the flow resistance. ${ }^{[7,24]}$ Hydraulic permeability was equal to $5.9 \times 10^{-13} \mathrm{~m}^{2}$ and was close to the values obtained by Yao et al. ${ }^{[24]}$ and Carvalho et al. ${ }^{[34]}$ for polyacrylamide cryogels.

The residence time distribution (RTD) was determined at different surface flow velocities in the mobile phase (Fig. 5), with the widest peaks obtained at the lowest velocities.

The values of the axial dispersial coefficients $\left(D_{a x}\right)$ were calculated, and the results are shown in Fig. 6 . The $D_{a x}$ values varied from $10^{-8}$ to $10^{-5} \mathrm{~m}^{2} / \mathrm{s}$ and are similar to the range of values obtained by Yao et al., ${ }^{[4,24]}$ Carvalho et al. ${ }^{[34]}$, and Machado et al. ${ }^{[5]}$ for supermacroporous cryogels, indicating that axial dispersion is weak in the affinity column.

Height values equivalent to a theoretical plate (HETP) of the RTD were calculated. These values were between 0.04 and $0.05 \mathrm{~mm}$ and were less than those obtained by other authors. ${ }^{[5,24,34]}$

The internal structure of the affinity cryogel is presented in Fig. 7. The pore structure of the affinity cryogel was uniform, interconnected, and with pore diameters varying from 10 to $80 \mu \mathrm{m}$. The produced cryogel monoliths presented a percentage of macropores (porosity, $\varnothing$ ) around $74.1 \% \pm 0.04$ and swelling capacity $\left(S_{w / w}\right)$ of $14.55 \pm 0.15(\mathrm{~kg} / \mathrm{kg})$. These values were close to those found by Carvalho et al. ${ }^{[34]}$ for polyacrilamide cryogels.

\section{Conclusions}

A low-cost and highly selective affinity cryogel was developed for purifying LYZ from CEW. Tris ligand groups were attached to the free epoxy groups on the cryogel surface, resulting in binding sites available for specific interactions with the amino acids aspartic acid 52, 


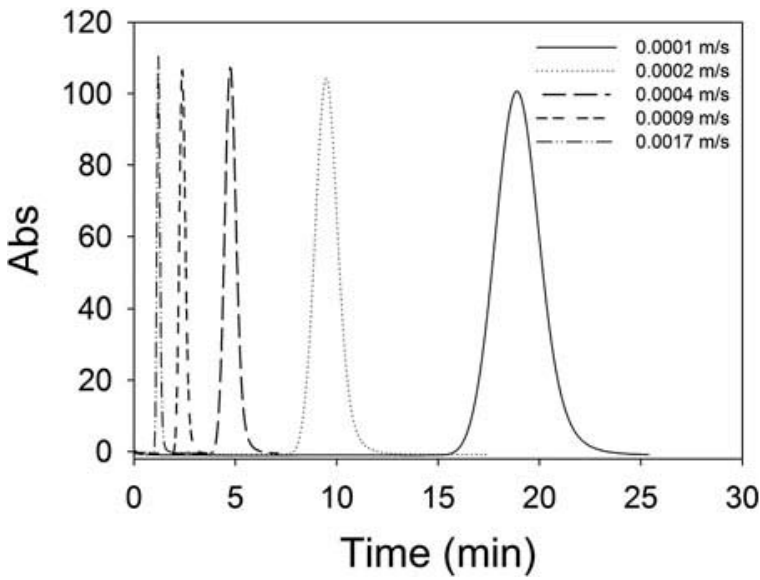

Figure 5. Residence time distribution curves at different mobile phase surface velocities $\left(U_{L}\right)$ through the affinity cryogel column.

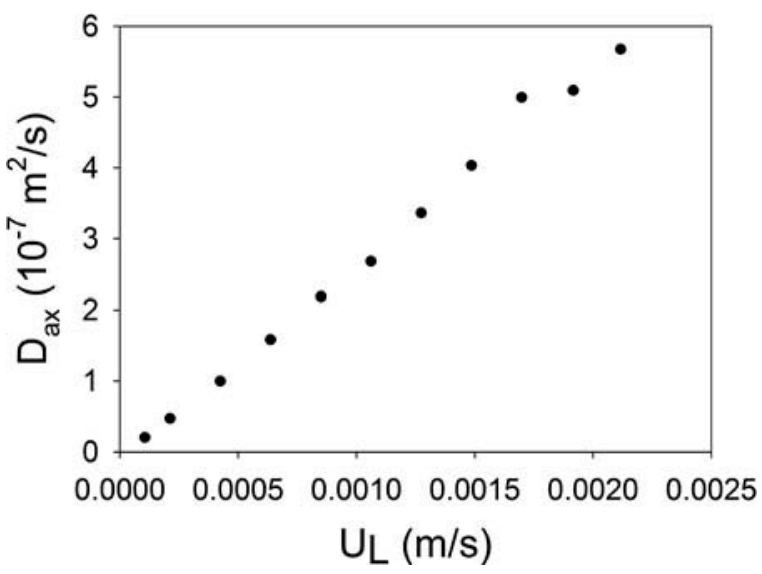

Figure 6. Axial dispersion coefficients $\left(D_{a x}\right)$ at different mobile phase surface velocities $\left(U_{L}\right)$ through the affinity cryogel column.

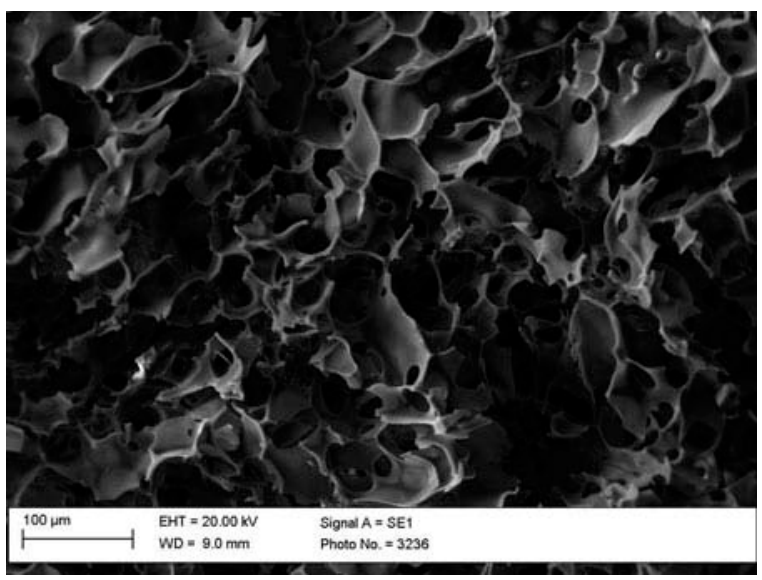

Figure 7. SEM micrograph of affinity cryogel containing the Tris ligand group. glutamic acid 35, and Alanine 107 of lysozyme. The affinity cryogel showed desirable morphological and hydrodynamic properties as a highly porous structure, with high permeability and low coefficient of axial dispersion. The chromatographic separation of LYZ from CEW solution using the affinity cryogel column was carried out in a single step. The affinity cryogel column presented highly specific binding capacity for LYZ, since the LYZ purified from CEW had purity above $78 \%$ and $97.0 \%$ recovery. The purification strategy using inexpensive ligand groups such as Tris makes it feasible to produce LYZ preparations from CEW by affinity chromatography.

\section{Funding}

The authors thank CAPES, CNPq and FAPEMIG and FAPESB for their financial support.

\section{References}

[1] Türkmen, D.; Denizli, A. (2014). PHEMA based composite cryogels with loaded hydrophobic beads for lysozyme purification. Colloids and Surfaces $B$ : Biointerfaces, 123: 859-865.

[2] Kumar, A.; Bansal, V.; Andersson, J.; Roychoudhury, P. K.; Mattiasson, B. (2006). Supermacroporous cryogel matrix for integrated protein isolation: Immobilized metal affinity chromatographic purification of urokinase from cell culture broth of a human kidney cell line. Journal of Chromatography A, 1103 (1): 35-42.

[3] Quan, L.; Cao, Q.; Li, Z.; Li, N.; Li, K.; Liu, F. (2009). Highly efficient and low-cost purification of lysozyme: A novel tris(hydroxymethyl)aminomethane immobilized affinity column. Journal of Chromatography B, 877 (7): 594-598.

[4] Yao, K.; Shen, S.; Yun, J.; Wang, L.; He, X.; Yu, X. (2006). Preparation of polyacrylamide-based supermacroporous monolithic cryogel beds under freezing-temperature variation conditions. Chemical Engineering Science, 61 (20): 6701-6708.

[5] Machado, A.P.D.F.; Minim, L.A.; Fontan, R.D.C.I.; Minim, V.P.R.; Gonçalves, G.R.F.; Mól, P.C.G. (2015). Adsorptive behavior of $\alpha$-lactalbumin on cationexchange supermacroporous monolithic column. Fluid Phase Equilibria, 401: 64-69.

[6] Altıntaş, E.B.; Tüzmen, N.; Candan, N.; Denizli, A. (2007). Use of magnetic poly(glycidyl methacrylate) monosize beads for the purification of lysozyme in batch system. Journal of Chromatography B, 853 (12): 105-113.

[7] Yao, K.; Yun, J.; Shen, S.; Chen, F. (2007). In-situ graftpolymerization preparation of cation-exchange supermacroporous cryogel with sulfo groups in glass columns. Journal of Chromatography A, 1157 (1-2): 246-251.

[8] Cömert, Ş.C.; Odabaşı, M. (2014). Investigation of lysozyme adsorption performance of $\mathrm{Cu} 2+$-attached PHEMA beads embedded cryogel membranes. Materials Science and Engineering: C, 34: 1-8. 
[9] Savina, I.N.; Mattiasson, B.; Galaev, I.Y. (2005). Graft polymerization of acrylic acid onto macroporous polyacrylamide gel (cryogel) initiated by potassium diperiodatocuprate. Polymer, 46 (23): 9596-9603.

[10] Şenel, S.; Elmas, B.; Çamlı, T.; Andaç, M.; Denizli, A. (2004). Poly(hydroxyethylmethacrylate-N-methacryloyl-(L)-histidine-methyl-ester) based metal-chelate affinity adsorbent for separation of lysozyme. Separation Science and Technology, 39 (16): 3783-3795.

[11] Arica, M.Y.; Denizli, A. (2000). Performance of different metal-dye chelated affinity adsorbents of poly(2hydroxyethyl methacrylate) in lysozyme separation. Separation Science and Technology, 35 (14): 2243-2257.

[12] Uygun, M.; Uygun, D.A.; Altunbaş, C.; Akgöl, S.; Denizli, A. (2014). Dye attached nanoparticles for lysozyme adsorption. Separation Science and Technology, 49 (8): 1270-1278.

[13] Liburdi, K.; Benucci, I.; Palumbo, F.; Esti, M. (2016). Lysozyme immobilized on chitosan beads: Kinetic characterization and antimicrobial activity in white wines. Food Control, 63: 46-52.

[14] Corradini, C.; Alfieri, I.; Cavazza, A.; Lantano, C.; Lorenzi, A.; Zucchetto, N.; Montenero, A. (2013). Antimicrobial films containing lysozyme for active packaging obtained by sol-gel technique. Journal of Food Engineering, 119 (3): 580-587.

[15] Kubiak-Ossowska, K.; Mulheran, P.A. (2010). Mechanism of hen egg white lysozyme adsorption on a charged solid surface. Langmuir, 26 (20): 15954-15965.

[16] Chang, Y.-K.; Chang, I.-P. (2006). Method development for direct recovery of lysozyme from highly crude chicken egg white by stirred fluidized bed technique. Biochemical Engineering Journal, 30 (1): 63-75.

[17] Ghosh, R. (2003). Purification of lysozyme by microporous PVDF membrane-based chromatographic process. Biochemical Engineering Journal, 14 (2): 109-116.

[18] Ghosh, R.; Silva, S.S.; Cui, Z. (2000). Lysozyme separation by hollow-fibre ultrafiltration. Biochemical Engineering Journal, 6 (1): 19-24.

[19] Kumar, A.; Plieva, F.M.; Galaev, I.Y.; Mattiasson, B. (2003). Affinity fractionation of lymphocytes using a monolithic cryogel. Journal of Immunological Methods, 283 (1-2): 185-194.

[20] Quan, L.; Wei, D.; Jiang, X.; Liu, Y.; Li, Z.; Li, N.; Li, K.; Liu, F.; Lai, L. (2008). Resurveying the Tris buffer solution: The specific interaction between tris(hydroxymethyl)aminomethane and lysozyme. Analytical Biochemistry, 378 (2): 144-150.

[21] Bradford, M.M. (1976). A rapid and sensitive method for the quantitation of microgram quantities of protein utilizing the principle of protein-dye binding. Analytical Biochemistry, 72 (1): 248-254.

[22] Liao, Y.-H.; Brown, M.B.; Martin, G.P. (2001). Turbidimetric and HPLC assays for the determination of formulated lysozyme activity. Journal of Pharmacy and Pharmacology, 53 (4): 549-554.
[23] Laemmli, U.K. (1970). Cleavage of structural proteins during the assembly of the head of bacteriophage T4. Nature, 227 (5259): 680-685.

[24] Yao, K.; Yun, J.; Shen, S.; Wang, L.; He, X.; Yu, X. (2006). Characterization of a novel continuous supermacroporous monolithic cryogel embedded with nanoparticles for protein chromatography. Journal of Chromatography A, 1109 (1): 103-110.

[25] Arvidsson, P.; Plieva, F.M.; Lozinsky, V.I.; Galaev, I.Y.; Mattiasson, B. (2003). Direct chromatographic capture of enzyme from crude homogenate using immobilized metal affinity chromatography on a continuous supermacroporous adsorbent. Journal of Chromatography A, 986 (2): 275-290.

[26] Zhang, G.; Cao, Q.; Li, N.; Li, K.; Liu, F. (2011). Tris (hydroxymethyl)aminomethane-modified magnetic microspheres for rapid affinity purification of lysozyme. Talanta, 83 (5): 1515-1520.

[27] Kadesch, R.G. (1946). Reaction of 3,4-Epoxy-1-butene with methanol. Direction and mechanism of ring opening. Journal of the American Chemical Society, 68 (1): 41-45.

[28] Yakabe, S. (2010). One-pot system for reduction of epoxides using $\mathrm{NaBH} 4, \mathrm{PdCl} 2$ catalyst, and moist alumina. Synthetic Communications, 40 (9): 1339-1344.

[29] Cao, Q.; Yin, Y.; Quan, L.; Li, N.; Li, K.; Liu, F. (2011). Weak affinity ligands selection using quartz crystal microbalance biosensor: multi-hydroxyl amine ligands for protein separation. Analytica Chimica Acta, 703 (2): 250-256.

[30] Bereli, N.; Andaç, M.; Baydemir, G.; Say, R.; Galaev, I. Y.; Denizli, A. (2008). Protein recognition via ioncoordinated molecularly imprinted supermacroporous cryogels. Journal of Chromatography A, 1190 (1-2): 1826.

[31] Damodaran, S.; Anand, K.; Razumovsky, L. (1998). Competitive adsorption of egg white proteins at the air-water interface: Direct evidence for electrostatic complex formation between lysozyme and other egg proteins at the interface. Journal of Agricultural and Food Chemistry, 46 (3): 872-876.

[32] Lechevalier, V.; Croguennec, T.; Pezennec, S.; GuérinDubiard, C.; Pasco, M.; Nau, F. (2005). Evidence for synergy in the denaturation at the air-water interface of ovalbumin, ovotransferrin and lysozyme in ternary mixture. Food Chemistry, 92 (1): 79-87.

[33] Başar, N.; Uzun, L.; Güner, A.; Denizli, A. (2007). Lysozyme purification with dye-affinity beads under magnetic field. International Journal of Biological Macromolecules, 41 (3): 234-242.

[34] Carvalho, B.M.A.; Carvalho, L.M.; Silva Jr, W.F.; Minim, L.A.; Soares, A.M.; Carvalho, G.G.P.; Da Silva, S.L. (2014). Direct capture of lactoferrin from cheese whey on supermacroporous column of polyacrylamide cryogel with copper ions. Food Chemistry, 154: $308-314$. 